\title{
PERENCANAAN DINDING PENAHAN TANAH PADA JALAN GUBERNUR SYARKAWI (SP. EMPAT HANDIL BAKTI - BYPASS BANJARMASIN)
}

\author{
Adhi Surya ${ }^{1}$, Muhammad Fikri Azhar ${ }^{2}$ dan Abdurrahman ${ }^{3}$ \\ ${ }^{123}$ Program Studi Teknik Sipil, Fakultas Teknik, \\ Universitas Islam Kalimantan Muhammad Arsyad Al Banjari Banjarmasin \\ E-mail : adhisuryastmt@gmail.com/HP+6287782738533, \\ fkrazr@gmail.com/HP : +6281251086335
}

\begin{abstract}
ABSTRAK
Dinding penahan tanah adalah suatu konstruksi untuk menahan tekanan tanah lateral yang terjadi akibat adanya perbedaan tinggi antara permukaan tanah dan beban luar. Pasangan batu merupaan salah satu jenis dinding penahan tanah yang sering digunakan di lapangan. Penelitian ini bertujuan mendapatkan desain pasangan batu pada bahu jalan untuk membantu menciptakan pelayanan jalan yang aman, nyaman dan lancar bagi pengguna jalan. Penelitian ini berlokasikan pada ruas Jalan Gubernur Syarkawi (Km 31+000 s.d $\mathrm{Km} 32+000$ ). Ada dua tahap dalam penelitian ini, yaitu: 1) Mendesain dimensi pasangan batu, perhitungan tekanan tanah lateral dengan teori Rankine, selanjutnya kontrol stabilitas terhadap geser, guling dan keruntuhan daya dukung; 2) Perhitungan daya dukung ultimit cerucuk galam dengan memperhatikan efisensi tiang cerucuk galam. Hasil dari penelitian ini berupa : 1) desain pasangan batu tipe 1,40 $\mathrm{m}$ dengan kontrol stabilitas $F_{g s}=13,98, F_{g l}=6,75, F=5,12$, desain pasangan batu tipe $1,50 \mathrm{~m}$ dengan kontrol stabilitas $F_{g s}=8,17, F_{g l}=5,85, F=4,50$, desain pasangan batu tipe 1,60 $m$ dengan kontrol stabilitas $F_{g s}=5,69, F_{g l}=5,13, F=3,97 ; 2$ ) desain fondasi tiang cerucuk galam sebanyak enam belas tiang galam berdiameter $8 / 12 \mathrm{~cm}$, dan kedalaman tiang galam sebesar 6,00 $\mathrm{m}$.
\end{abstract}

Kata Kunci : Pasangan Batu, Cerucuk Galam, Dinding Penahan, Perencanaan

\section{ABSTRACT}

Retaining wall is a construction to withstand lateral soil pressure that occurs due to the high difference between ground surface and external load. Pairs of stone is one type of retaining wall that often used in the field. This study aims to obtain a stone pair design on the roadside to help create safe, comfortable and smoothness road services for road users. This research is located on Syarkawi Governor's Street (Km 31+000 to Km $32+000)$. There are two stages in this research, namely: 1) Designing dimensions of stone pairs, analysis of lateral earth pressure calculations with Rankine theory, then controlling stability of shear, rolling and collapse of bearing capacity; 2) Analysis of ultimite carrying capacity of the galam piles by considering the efficiency. The results of this study are: 1) there is three design of stone pairs, which is $1.40 \mathrm{~m}$ type with stability control $F_{g s}=13,98, F_{g l}=6.75, F=5.12,1.50$ m type with stability control $F_{g s}=8,17$, $F_{g l}=5.85, F=4.50,1.60 m$ type with stability control $F_{g s}=5,69, F_{g l}=5.13, F=3.97$; 2) the foundation design of the galam piles consists of sixteen galams $8 / 12 \mathrm{~cm}$ in diameter, and the depth of the galam piles is $6.00 \mathrm{~m}$.

Keywords: Stone Pairs, Galam Piles, Retaining Walls, Planning 


\section{PENDAHULUAN}

\section{Latar Belakang}

Jalan Gubernur Syarkawi termasuk jalan kelas I yang menghubungkan antara Jalan Simpang Empat Handil Bakti ke Jalan A Yani Kilometer 17 (Bypass Banjarmasin). Pada jalan ini Km 31+000 s.d Km 32+000 sudah dilakukan peningkatan jalan beraspal dengan lebar badan jalan tujuh meter dan lebar bahu jalan kiri dan kanan tiga meter. Namun dari pengamatan sementara mengenai kondisi bahu jalan di Jalan Gubernur Syarkawi dapat terjadi kemungkinan longsor akibat adanya perbedaan tinggi antara bahu jalan dengan tanah dasar rawa, dimana hal tersebut tentu nantinya akan merusak konstruksi badan jalan. Dengan melihat permasalahan diatas, maka dalam ilmu teknik sipil permasalahan tersebut dapat diatasi dengan mendesain suatu konstruksi berupa dinding penahan tanah yang berfungsi menahan dan mencegah keruntuhan tanah yang miring. Dinding penahan tanah menahan tekanan tanah lateral yang terjadi akibat adanya perbedaan ketinggian tanah. Menurut Riska Rahmawati Djunaedi (2020), salah satu dinding penahan tanah yang umum digunakan untuk ketinggian yang pendek adalah dinding penahan tipe gravitasi. Suhudi, dkk (2017), berpendapat bahwa perhitungan tekanan tanah lateral adalah sebuah parameter perencanaan yang penting didalam sejumlah persoalan teknik pondasi, dinding penahan dan konstruksi-konstruksi lain yang ada di bawah tanah. Syafruddin (2004), menyebutkan dalam penelitiannya, bahwa terdapat salah satu teori yang dapat digunakan untuk perhitungan tekanan tanah lateral yaitu Teori Rankine. Dalam penelitian oleh Dedek Solehuddin, dkk (2018), Perancangan dinding penahan tanah harus memenuhi faktor aman terhadap tiga kontrol stabilitas. faktor aman terhadap stabilitas penggulingan yaitu $F_{g l} \geq 2$ untuk tanah dasar kohesif. Muhammad Nasrudin dan Siswoyo (2019), faktor aman terhadap stabilitas penggeseran adalah $F_{g s} \geq 2$ untuk tekanan tanah pasif diperhitungkan. Sedangkan kontrol faktor aman terhadap stabilitas keruntuhan daya dukung adalah $F \geq 3$. Dari penelitian-penelitian diatas, maka penelitian ini mendesain dinding penahan tanah tipe gravitasi berupa pasangan batu untuk bahu jalan di Jalan Gubernur Syarkawi. Dengan adanya pasangan batu ini, kemungkinan kerusakan pada konstruksi badan jalan akibat bahu jalan yang longsor dapat diatasi, sehingga membantu menciptakan pelayanan jalan yang aman, nyaman dan lancar bagi kendaraan yang melintasi jalan tersebut.

\section{Tujuan Penelitian}

Secara spesifik tujuan utama yang akan dicapai berdasarkan permasalahan dari penelitian ini adalah sebagai berikut :

1. Mendapatkan desain pasangan batu untuk dinding penahan tanah pada bahu jalan.

2. Mendapatkan desain fondasi tiang cerucuk galam sebagai tambahan perkuatan daya dukung tanah terhadap beban konstruksi pasangan batu.

\section{METODE PENELITIAN}

\section{Lokasi dan Waktu Penelitian}

Lokasi penelitian dilakukan pada Jalan Gubernur Syarkawi (Sp. Empat Handil Bakti Bypass Banjarmasin) ( $\mathrm{Km} \mathrm{31+000} \mathrm{S.d} \mathrm{Km} \mathrm{32+000).} \mathrm{Waktu} \mathrm{penelitian} \mathrm{disesuaikan}$ dengan kalender akademik Universitas Islam Kalimantan Muhammad Arsyad Al Banjari Banjarmasin. 


\section{Alat dan Bahan Penelitian}

Peralatan yang digunakan dalam pelaksanaan penelitian ini terdiri dari roll meter $50 \mathrm{~m}$ dan 7,50 m, kayu panjang $2 \mathrm{~m}$, smartphone, laptop, printer, alat tulis. Bahan yang digunakan dalam pelaksanaan penelitian ini antara lain kertas HVS 80 gsm ukuran A4 dan buku tulis kecil.

\section{Tahapan Penelitian}

Tahapan-tahapan pada penelitian ini adalah sebagai berikut :

1. Tahap persiapan dari rangkaian kegiatan sebelum memulai pengumpulan dan pengolahan data. Tahap persiapan ini meliputi, yaitu :

a. Studi Literatur

Mengumpulkan, membaca, dan menganalisis sumber-sumber pustaka yang berkaitan dengan judul dan tema penelitian ini, baik melalui buku, makalah hasil seminar, jurnal, karya tulis maupun bahan-bahan yang didapat dari bangku perkuliahan. Hal ini bertujuan untuk memberikan pengetahuan dan pemahaman terhadap permasalahan yang diangkat, sehingga didapat suatu landasan teori yang kuat dan dapat dipertanggung jawabkan.

b. Survey Pendahuluan

Kegiatan survey di lapangan untuk menghimpun data-data lapangan secara visual di lokasi tempat penelitian dilakukan. Adapun hal-hal yang dilakukan dalam survey pendahuluan, yaitu :

1) Melihat langsung kondisi lapangan secara umum.

2) Menentukan titik awal dan titik akhir penelitian.

3) Mengukur lebar badan jalan dan lebar bahu jalan.

4) Pengukuran topografi untuk penentuan tinggi konstruksi pasangan batu.

5) Mengambil foto-foto kondisi lapangan.

2. Tahap pengumpulan data, terdiri dari :

a. Data Primer

Data primer adalah data-data yang diperoleh langsung di lapangan melalui interaksi langsung dengan objek penelitian. Data primer pada penelitian ini berupa melihat kondisi lapangan, mengukur lebar badan jalan dan lebar bahu jalan, serta pengukuran topografi untuk penentuan tinggi konstruksi pasangan batu.

b. Data Sekunder

Data sekunder adalah data yang di dapat dari studi pustaka, makalah hasil seminar, jurnal, karya tulis dan laporan instansi pemerintah maupun swasta yang terkait. Data sekunder yang diperlukan berupa data beban jalan kelas I, data pasangan batu, data tanah lapisan pondasi agregat kelas $\mathrm{S}$, data tanah timbunan pilihan, data tanah dasar dan data sondir.

3. Data-data yang sudah dikumpulkan, selanjutnya dilakukan analisis sebagai berikut:

a. Desain pasangan batu untuk dinding penahan tanah pada bahu jalan.

1) Memperkirakan dimensi pasangan batu.

2) Menghitung tekanan tanah lateral yang terjadi pada pasangan batu dengan menggunakan teori Rankine.

Teori Rankine dalam menentukan tekanan tanah lateral didasarkan pada asumsi yang terpenting adalah antara permukaan dinding dengan tanah tidak ada gesekan (licin), tanah urugan tidak berkohesi $(c)$, dan tanah dalam kedudukan keseimbangan plastis. Apabila tanah yang bekerja di dinding berupa tanah homogen, sehingga besarnya tekanan horizontal yang bekerja pada dinding tersebut, yaitu : 
$P_{a}=1 / 2 h_{1}^{2} \gamma K_{a}$

$P_{p}=1 / 2 h_{2}^{2} \gamma K_{p}$

keterangan :

$P_{a}=$ Tekanan tanah aktif

$P_{p}=$ Tekanan tanah pasif

$h=$ Tebal lapisan tanah

$\gamma=$ Berat volume lapisan tanah

$K_{a}=$ Koefisien tekanan tanah aktif

$K_{p}=$ Koefisien tekanan tanah pasif

Untuk mencari besarnya koefisien tanah aktif $\left(K_{a}\right)$ dan koefisien tanah pasif $\left(K_{p}\right)$ dengan permukaan tanah datar (sudut kemiringan nol), maka digunakan persamaan berikut :

$K_{a}=\operatorname{tg}^{2}\left(45^{\circ}-\frac{\emptyset}{2}\right)$

$K_{p}=\operatorname{tg}^{2}\left(45^{\circ}+\frac{\emptyset}{2}\right)$

keterangan :

$K_{a}=$ Koefisien tekanan tanah aktif

$K_{p}=$ Koefisien tekanan tanah pasif

$\phi=$ Sudut geser tanah

3) Menghitung gaya-gaya yang bekerja pada pasangan batu.

4) Mengontrol stabilitas dinding penahan tanah terhadap bahaya penggeseran, bahaya penggulingan, dan bahaya keruntuhan daya dukung tanah.

Kontrol terhadap tiga stabilitas :

- Faktor aman terhadap penggeseran $\left(F_{g s}\right)$ apabila tekanan tanah pasif dipehitungkan, didefinisikan sebagai berikut :

$F_{g s}=\frac{\sum R_{h}}{\sum P_{h}}=\frac{(c \cdot B)+\left(\sum W \cdot \operatorname{tg} \delta\right)}{\sum P_{h}}$

keterangan :

$F_{g s}=$ Faktor aman terhadap penggeseran

$c_{d}=$ Gesekan kohesi tanah dengan faktor adhesi, diambil dari $1 / 3$ s.d 2/3 $c$

$B=$ Lebar bawah dinding penahan tanah

$\Sigma W=$ Total berat sendiri dinding penahan tanah

$\delta=$ Sudut gesek, diambil dari $1 / 3$ s.d $2 / 3 \phi$

$\Sigma P a \quad=$ Tekanan tanah aktif

dengan $\Sigma P_{h}=\Sigma P_{a}-\Sigma P_{p}$

keterangan :

$\Sigma P_{h} \quad=$ Jumlah gaya-gaya horizontal

$P_{a}=$ Tekanan tanah aktif

$P_{p}=$ Tekanan tanah pasif

- Faktor aman terhadap penggulingan $\left(\mathrm{F}_{\mathrm{gl}}\right)$ apabila tekanan tanah pasif dipehitungkan, didefinisikan sebagai berikut :

$F_{g l}=\frac{\sum M w}{\sum M g}$

keterangan :

$F_{g l}=$ Faktor aman terhadap penggulingan

$\Sigma M_{w}=$ Momen terhadap berat sendiri dinding penahan tanah

$\Sigma M_{a}=$ Momen terhadap tekanan tanah aktif 
dengan $\Sigma M_{g}=\Sigma M_{a}-\Sigma M_{p}$

keterangan :

$\Sigma M_{g}=$ Jumlah momen yang mengakibatkan penggulingan

$\Sigma M_{a}=$ Momen terhadap tekanan tanah aktif

$\Sigma M_{p}=$ Momen terhadap tekanan tanah pasif

- Daya dukung ultimit adalah tekanan maksimum yang dapat diterima oleh tanah akibat beban yang bekerja tanpa menimbulkan keruntuhan geser pada tanah pendukung tepat di bawah dan sekeliling dinding. Untuk menghitung daya dukung ultimit dengan persamaan Terzaghi sebagai berikut :

$q_{u l t}=c \cdot N_{c}+D_{f} \cdot \gamma \cdot N_{q}+0,5 \cdot B \cdot N_{\gamma}$

keterangan :

$q_{u l t}=$ Daya dukung ultimit

$c=$ Nilai kohesi tanah

$D_{f}=$ Kedalaman fondasi

$\gamma=$ Berat volume tanah

$B$ = Lebar bawah dinding penahan tanah

$N_{c}, N_{q}, N \gamma=$ Faktor daya dukung tanah (dimana nilai - nilai merupakan

fungsi besarnya sudut geser dalam $(\phi)$ yang diberikan oleh Terzaghi).

Untuk tanah dengan keruntuhan geser lokal nilai $c$ diganti menjadi $c^{\prime}=2 / 3 c$ dan nilai $\phi$ diganti menjadi $\phi^{\prime}=2 / 3 \phi$.

Faktor aman terhadap keruntuhan daya dukung tanah didefinisikan sebagai berikut.

$F=\frac{q u l t}{q \max }$

keterangan :

$F=$ Faktor aman terhadap keruntuhan daya dukung tanah

$q_{u l t}=$ Daya dukung ultimit

$q_{\text {max }}=$ Tekanan akibat beban struktur

Apabila dihitung berdasarkan lebar pondasi efektif, yaitu tekanan tanah pondasi ke tanah dasar terbagi rata secara sama, maka :

$$
\begin{aligned}
& \mathrm{q}_{\max }=\frac{\sum W}{B}\left[1+\frac{6 e}{B}\right] \text { bila } e \leq \frac{B}{6} \\
& q_{\max }=\frac{2 v}{3(B-2 e)} \text { bila } e \geq \frac{B}{6} \ldots \ldots . . .
\end{aligned}
$$

b. Desain fondasi tiang cerucuk galam sebagai tambahan perkuatan daya dukung tanah terhadap beban konstruksi pasangan batu.

1) Memperkirakan diameter galam, jumlah galam, dan kedalaman galam.

2) Menghitung daya dukung ultimit tiang galam tunggal dengan persamaan Meyerhof.

Fondasi tiang cerucuk galam merupakan salah satu jenis fondasi yang biasanya diaplikasikan di daerah dengan kondisi tanah yang lunak dan kurang stabil. Persamaan yang digunakan untuk menghitung daya dukung ultimit tiang galam tunggal berdasarkan data sondir menurut Meyerhof adalah sebagai berikut :

$Q_{u l t}=\frac{A_{p} \cdot q_{c}}{S_{f 1}}+\frac{A_{s} \cdot F_{t o t a l}}{S_{f 2}}$

keterangan :

$Q_{u l t}=$ Daya dukung ultimit tiang galam tunggal

$A_{p}=$ Luas permukaan tiang galam

$A_{s}=$ Keliling tiang galam

$q_{c}=$ Perlawanan konus 
$F_{\text {total }}=$ Jumlah hambatan pelekat

$S_{f l}=$ Angka keamanan untuk tahanan ujung

$S_{f 2}=$ Angka keamanan untuk gesekannya

3) Menghitung efesiensi tiang cerucuk galam dengan persamaan Converse Labarre. Untuk menghitung efisiensi tiang cerucuk galam dapat menggunakan persamaan Converse Labarre, yaitu :

$E_{g}=1-\theta \frac{\left(n^{\prime}-1\right) m^{\prime}+\left(m^{\prime}-1\right) n^{\prime}}{90 \cdot m^{\prime} \cdot n^{\prime}}$

keterangan :

$E_{g}=$ Efisiensi tiang cerucuk galam

$\theta=\operatorname{arctg}(d / s)$, dalam derajat

$m^{\prime}=$ Jumlah baris tiang galam

$n^{\prime}=$ Jumlah kolom tiang galam

4) Menghitung daya dukung ultimit tiang cerucuk galam dengan memperhatikan efesiensi tiang cerucuk galam.

Persamaan untuk menentukan daya dukung ultimit tiang cerucuk galam dengan memperhatikan efisiensi tiang cerucuk galam adalah sebagai sebagai berikut :

$Q_{g}=n \cdot Q_{\text {ult }} . E_{g}$

keterangan :

$Q_{g}=$ Daya dukung ultimit tiang cerucuk galam dengan memperhatikan efisiensi tiang cerucuk

$\begin{aligned} & \text { galam } \\ n= & \text { Jumlah tiang galam } \\ Q_{u l t}= & \text { Daya dukung ultimit tiang galam tunggal } \\ E_{g}= & \text { Nilai efisiensi tiang cerucuk galam }\end{aligned}$

\section{HASIL DAN PEMBAHASAN}

\section{Desain Pasangan Batu Untuk Dinding Penahan Tanah Pada Bahu Jalan.}

1. Parameter Data Desain Pasangan Batu

Data-data yang telah dikumpulkan untuk mendesain pasangan batu dapat dilihat pada

Tabel 1. berikut.

Tabel 1. Data-data Desain Pasangan Batu

\begin{tabular}{|c|c|c|c|}
\hline $\begin{array}{c}\mathrm{N} \\
\mathrm{O}\end{array}$ & \multicolumn{2}{|c|}{ Uraian Data } & Sumber Data \\
\hline 1 & $\begin{array}{c}\text { Beban Di Atas } \\
\text { Pasangan Batu }\end{array}$ & $q=2,18 \mathrm{kN} / \mathrm{m}^{2}$ & $\begin{array}{c}\text { UU LLAJ No. 22 Tahun 2009 } \\
\text { Pasal 19 Ayat 2 Beban Klasifikasi } \\
\text { Jalan Kelas I }\end{array}$ \\
\hline 2 & Berat Volume Air & $\gamma_{w}=9,81 \mathrm{kN} / \mathrm{m}^{3}$ & $\begin{array}{c}\text { Buku Mekanika Tanah I (Edisi } \\
\text { Ketiga) oleh Hardiyatmo }\end{array}$ \\
\hline 3 & $\begin{array}{c}\text { Berat Volume } \\
\text { Gungan Batu }\end{array}$ & $\gamma_{\beta}=21,57$ & $\begin{array}{c}\text { Peraturan Pembebanan Untuk } \\
\text { Gedung 1983 }\end{array}$ \\
\hline 4 & & & \\
\hline
\end{tabular}




\begin{tabular}{|c|c|c|c|}
\hline & $\begin{array}{c}\text { Berat Volume Lapis } \\
\text { Pondasi Agregat Kelas } \\
\text { S (Tanah 1) } \\
\end{array}$ & $\begin{array}{c}\gamma_{1}=20,99 \\
k N / m^{3}\end{array}$ & \multirow{2}{*}{$\begin{array}{l}\text { Laporan Job Mix Formula PT. } \\
\text { Multi Usaha Pembangunan }\end{array}$} \\
\hline 5 & $\begin{array}{l}\text { Berat Volume Tanah } \\
\text { Timbunan (Tanah 2) }\end{array}$ & $\begin{array}{c}\gamma_{2}=17,02 \\
k N / m^{3}\end{array}$ & \\
\hline 6 & Sudut Geser Tanah 1 & $\phi_{1}=40^{\circ}$ & \multirow{2}{*}{$\begin{array}{c}\text { Tabel 2.1 Korelasi Antara Sudut } \\
\text { Geser Dalam dengan Jenis Tanah } \\
\text { dari Buku Teknik Sipil oleh } \\
\text { Sunggono Kh }\end{array}$} \\
\hline 7 & Sudut Geser Tanah 2 & $\phi_{2}=40^{\circ}$ & \\
\hline 8 & $\begin{array}{l}\text { Berat Volume Tanah } \\
\text { Dasar (Tanah 3) }\end{array}$ & $\begin{array}{c}\gamma_{3}=15,00 \\
k N / m^{3}\end{array}$ & \multirow{3}{*}{$\begin{array}{l}\text { Laporan Praktikum Mektan II } \\
\text { ULM oleh Kelompok } 8 \text { Tahun } \\
2018\end{array}$} \\
\hline 9 & Nilai Kohesi Tanah 3 & $\begin{array}{c}c_{3}=15,49 \\
\mathrm{kN} / \mathrm{m}^{2}\end{array}$ & \\
\hline $\begin{array}{l}1 \\
0\end{array}$ & Sudut Geser Tanah 3 & $\phi_{3}=4,60^{\circ}$ & \\
\hline
\end{tabular}

Sumber: Analisis, 2020

2. Perencanaan Dimensi Pasangan Batu

Dalam perencanaan dimensi pasangan batu maka dilakukan pengukuran topografi dilakukan pada lokasi penelitian untuk mendapatkan ketinggian pasangan batu dengan lebar bahu jalan $4 \mathrm{~m}$. Sehingga direncanakan tiga tipe pasangan batu yang ditunjukkan pada Tabel 2. sebagai berikut.

Tabel 2. Dimensi Pasangan Batu

\begin{tabular}{|c|c|c|c|c|c|c|}
\hline No & Tipe Pasangan Batu & $H(m)$ & $L A(m)$ & $L B(m)$ & $D_{1}(m)$ & $D_{2}(m)$ \\
\hline 1 & Pasangan Batu A & 1,40 & 0,35 & 1,00 & 0,30 & 0,20 \\
\hline 2 & Pasangan Batu B & 1,50 & 0,35 & 1,00 & 0,30 & 0,20 \\
\hline 3 & Pasangan Batu C & 1,60 & 0,35 & 1,00 & 0,30 & 0,20 \\
\hline
\end{tabular}

Sumber: Hasil Analisis, 2020

3. Perhitungan Berat Sendiri Pasangan Batu dan Beban di Atasnya

Berat sendiri dan beban di atasnya serta momen berat sendiri berfungsi sebagai kekuatan dari konstruksi pasangan batu untuk membantu mencegah penggeseran akibat tekanan tanah aktif dan juga penggulingan akibat momen tekanan tanah aktif. Perhitungan berat sendiri pasangan batu dan beban di atasnya ditinjau per satu meter. Adapun hasil perhitungan berat dan momen dari ketiga tipe pasangan batu, masingmasing ditunjukkan pada Tabel 3. berikut. 
Tabel 3. Berat dan Momen Pasangan Batu

\begin{tabular}{|c|c|c|}
\hline Tipe Pasangan Batu & Berat $(k N)$ & Momen $(k N . m)$ \\
\hline Pasangan Batu A & $\square W=23,02$ & $\square M w=13,87$ \\
\hline Pasangan Batu B & $\square W=24,39$ & $\square M w=14,75$ \\
\hline Pasangan Batu C & $\square W=25,75$ & $\square M w=15,63$ \\
\hline
\end{tabular}

Sumber: Hasil Analisis, 2020

4. Perhitungan Tekanan Tanah Lateral

Perhitungan tekanan tanah lateral ditinjau per satu meter dengan menggunakan teori Rankine. Adapun hasil perhitungan koefisien tekanan tanah aktif maupun pasif dapat dilihat pada Tabel 4. berikut.

Tabel 4. Koefisien Tekanan Tanah Aktif dan Koefisien Tekanan Tanah Pasif

\begin{tabular}{|c|}
\hline Koefisien Tekanan Tanah \\
\hline$K_{a 1}=0,22$ \\
\hline$K_{a 2}=0,22$ \\
\hline$K_{p}=1,17$ \\
\hline Sumber: Hasil Analisis, 2020
\end{tabular}

Tekanan tanah aktif merupakan tekanan yang terjadi akibat dari tanah yang berada pada bagian belakang dinding mendorong dan menjauhi dinding hingga terjadi penggeseran. Sedangkan momen tekanan tanah aktif menyebabkan terjadinya penggulingan. Adapun hasil perhitungan tekanan tanah aktif dan momen tekanan tanah aktif dari ketiga tipe pasangan batu, masing-masing ditunjukkan pada Tabel 5. berikut.

Tabel 5. Tekanan dan Momen Tanah Aktif

\begin{tabular}{|c|c|c|}
\hline Tipe Pasangan Batu & $\begin{array}{c}\text { Tekanan Tanah } \\
\text { Aktif }(k N)\end{array}$ & $\begin{array}{c}\text { Momen Tekanan } \\
\text { Tanah Aktif }(k N . m)\end{array}$ \\
\hline Pasangan Batu A & $\square P a=4,32$ & $\square M a=2,17$ \\
\hline Pasangan Batu B & $\square P a=4,92$ & $\square M a=2,64$ \\
\hline Pasangan Batu C & $\square P a=5,55$ & $\square M a=3,16$ \\
\hline
\end{tabular}

Sumber: Hasil Analisis, 2020

Tekanan tanah pasif merupakan tekanan yang terjadi akibat dari tanah yang berada pada bagian depan dinding menahan dan mendesak ke arah dinding akibat terjadinya penggeseran oleh tekanan tanah aktif. Sedangkan momen tekanan tanah pasif melawan penggulingan akibat momen tekanan tanah aktif. Adapun hasil perhitungan tekanan tanah pasif dan momen tekanan tanah pasif dari ketiga tipe pasangan batu, masingmasing ditunjukkan pada Tabel 6. berikut. 
Tabel 6. Tekanan dan Momen Tanah Pasif

\begin{tabular}{|c|c|c|}
\hline Tipe Pasangan Batu & $\begin{array}{c}\text { Tekanan Tanah } \\
\text { Pasif }(k N)\end{array}$ & $\begin{array}{c}\text { Momen Tekanan } \\
\text { Tanah Pasif }(k N . m)\end{array}$ \\
\hline Pasangan Batu A & $\square P p=3,49$ & $\square M p=0,11$ \\
\hline Pasangan Batu B & $\square P p=3,49$ & $\square M p=0,11$ \\
\hline Pasangan Batu C & $\square P p=3,49$ & $\square M p=0,11$ \\
\hline
\end{tabular}

Sumber: Hasil Analisis, 2020

\section{Faktor Aman Terhadap Penggeseran}

Akibat tekanan tanah aktif pada bagian belakang pasangan batu yang mendorong pasangan batu, sehingga menyebabkan pasangan batu bergeser. Adapun hasil perhitungan faktor aman terhadap penggeseran dari ketiga tipe pasangan batu selengkapnya ditunjukkan pada Tabel 7. berikut.

Tabel 7. Faktor Aman Terhadap Penggeseran

\begin{tabular}{|c|c|c|}
\hline Tipe Pasangan Batu & $F_{g s} \square 2$ & Keterangan \\
\hline Pasangan Batu A & $13,98 \square 2$ & Aman \\
\hline Pasangan Batu B & $8,17 \square 2$ & Aman \\
\hline Pasangan Batu C & $5,69 \square 2$ & Aman \\
\hline
\end{tabular}

6. Faktor Aman Terhadap Penggulingan

Tekanan tanah aktif pada bagian belakang pasangan batu, cenderung menggulingkan pasangan batu dengan pusat rotasi pada ujung kaki depan. Adapun hasil perhitungan faktor aman terhadap penggulingan dari ketiga tipe pasangan batu selengkapnya ditunjukkan pada Tabel 8. berikut.

Tabel 8. Faktor Aman Terhadap Penggulingan

\begin{tabular}{|c|c|c|}
\hline Tipe Pasangan Batu & $F_{g l} \square 2$ & Keterangan \\
\hline Pasangan Batu A & $6,75 \square 2$ & Aman \\
\hline Pasangan Batu B & $5,85 \square 2$ & Aman \\
\hline Pasangan Batu C & $5,13 \square 2$ & Aman \\
\hline
\end{tabular}

7. Faktor Aman Terhadap Keruntuhan Daya Dukung Tanah

Keruntuhan daya dukung tanah terjadi akibat tekanan dari beban konstruksi pasangan batu yang terletak diatas tanah. Pada perhitungan daya dukung ultimit tanah, dimana jenis tanah dasar (tanah 3) adalah tanah lempung yang termasuk kategori tanah lunak maka keruntuhan yang terjadi adalah keruntuhan geser lokal. Hasil perhitungan faktor aman terhadap keruntuhan daya dukung tanah dari ketiga tipe pasangan batu selengkapnya ditunjukkan pada Tabel 9. berikut.

Tabel 9. Faktor Aman Terhadap Keruntuhan Daya Dukung Tanah

\begin{tabular}{|c|c|c|}
\hline Tipe Pasangan Batu & $F \square 3$ & Keterangan \\
\hline Pasangan Batu A & $5,12 \square 3$ & Aman \\
\hline Pasangan Batu B & $4,50 \square 3$ & Aman \\
\hline Pasangan Batu C & $3,97 \square 3$ & Aman \\
\hline
\end{tabular}




\section{Desain Fondasi Tiang Cerucuk Galam Sebagai Tambahan Perkuatan Daya Dukung} Tanah Terhadap Beban Konstruksi Pasangan Batu.

1. Parameter Data Desain Fondasi Tiang Cerucuk Galam

Data-data yang telah dikumpulkan dapat dilihat pada Tabel 10. berikut.

Tabel 10. Data-data Desain Fondasi Tiang Cerucuk Galam

\begin{tabular}{|c|c|c|c|}
\hline No & \multicolumn{2}{|c|}{ Uraian Data } & Sumber Data \\
\hline 1 & $\begin{array}{l}\text { Jumlah baris tiang cerucuk } \\
\text { galam }\end{array}$ & $m^{\prime}=4$ galam & \multirow{4}{*}{ Trials and Errors } \\
\hline 2 & $\begin{array}{l}\text { Jumlah kolom tiang cerucuk } \\
\text { galam }\end{array}$ & $n^{\prime}=4$ galam & \\
\hline 3 & Diameter tiang galam & $d=8 / 12 \mathrm{~cm}$ & \\
\hline 4 & Kedalaman tiang galam & $D=6,00 \mathrm{~m}$ & \\
\hline 5 & $\begin{array}{c}\text { Jarak antar tiang cerucuk } \\
\text { galam }\end{array}$ & $s=0,25 \mathrm{~m}$ & $\begin{array}{c}\text { Syarat } s \square 2,5 d \text { Buku Teknik } \\
\text { Pondasi II (Edisi Keempat) oleh } \\
\text { Hardiyatmo }\end{array}$ \\
\hline 6 & $\begin{array}{l}\text { Nilai perlawanan konus pada } \\
\text { kedalaman } 6,00 \mathrm{~m}\end{array}$ & $q_{c}=1,20 \mathrm{~kg} / \mathrm{cm}^{2}$ & \multirow{2}{*}{$\begin{array}{c}\text { Laporan Praktikum Mektan I } \\
\text { UNISKA oleh Kelompok } 8 \text { Tahun } \\
2019\end{array}$} \\
\hline 7 & $\begin{array}{c}\text { Jumlah hambatan pelekat } \\
\text { pada kedalaman } 6,00 \mathrm{~m}\end{array}$ & $\begin{array}{c}F_{\text {total }}=49,738 \\
\mathrm{~kg} / \mathrm{cm}\end{array}$ & \\
\hline
\end{tabular}

Sumber: Analisis, 2020

2. Perhitungan Perkuatan Daya Dukung Tanah

Fondasi tiang cerucuk galam berfungsi untuk memperkuat daya dukung tanah terhadap beban konstruksi pasangan batu. Adapun hasil perhitungan faktor aman terhadap perkuatan daya dukung tanah oleh fondasi tiang cerucuk galam dari ketiga tipe pasangan batu selengkapnya ditunjukkan pada Tabel 11. berikut.

Tabel 11. Faktor Aman Terhadap Perkuatan Daya Dukung Tanah

\begin{tabular}{|c|c|c|c|c|}
\hline Tipe Pasangan Batu & $Q_{u l t}(k N)$ & $E_{g}$ & $Q_{g} \square \square W$ & Keterangan \\
\hline Pasangan Batu A & 3,37 & 0,64 & $34,32 \square 23,02$ & Aman \\
\hline Pasangan Batu B & 3,37 & 0,64 & $34,32 \square 24,39$ & Aman \\
\hline Pasangan Batu C & 3,37 & 0,64 & $34,32 \square 25,75$ & Aman \\
\hline
\end{tabular}

Sumber: Hasil Analisis, 2020 
Gambar Desain Pasangan Batu Dengan Perkuatan Fondasi Tiang Cerucuk Galam

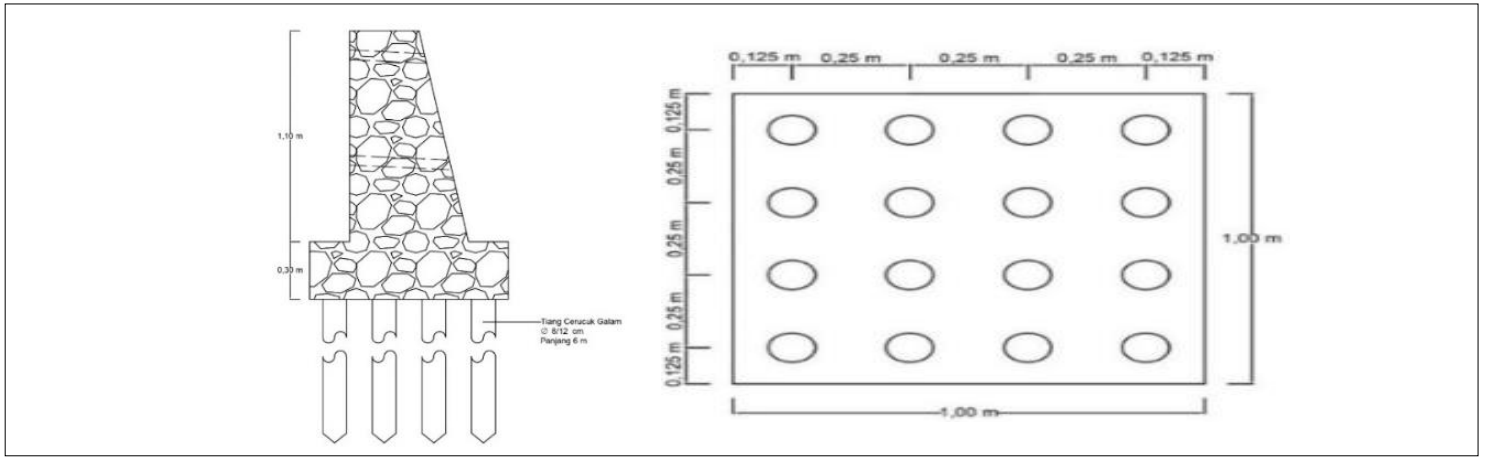

Gambar 1. Desain Pasangan Batu A

(Sumber: Hasil Analisis, 2020)

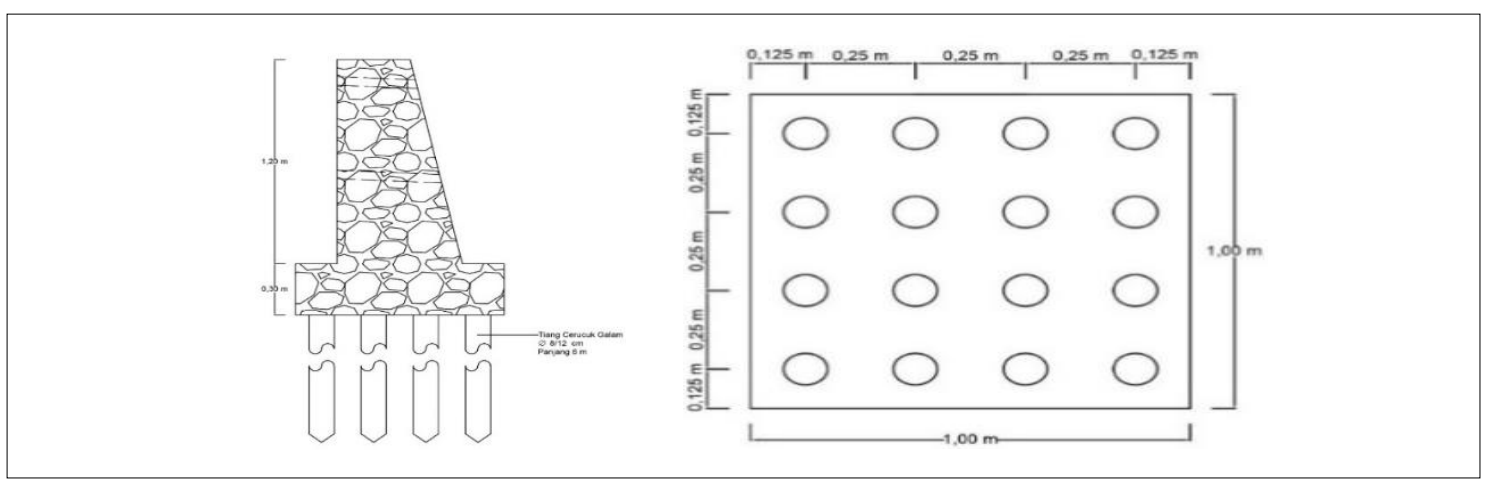

Gambar 2. Desain Pasangan Batu B

(Sumber: Hasil Analisis, 2020)

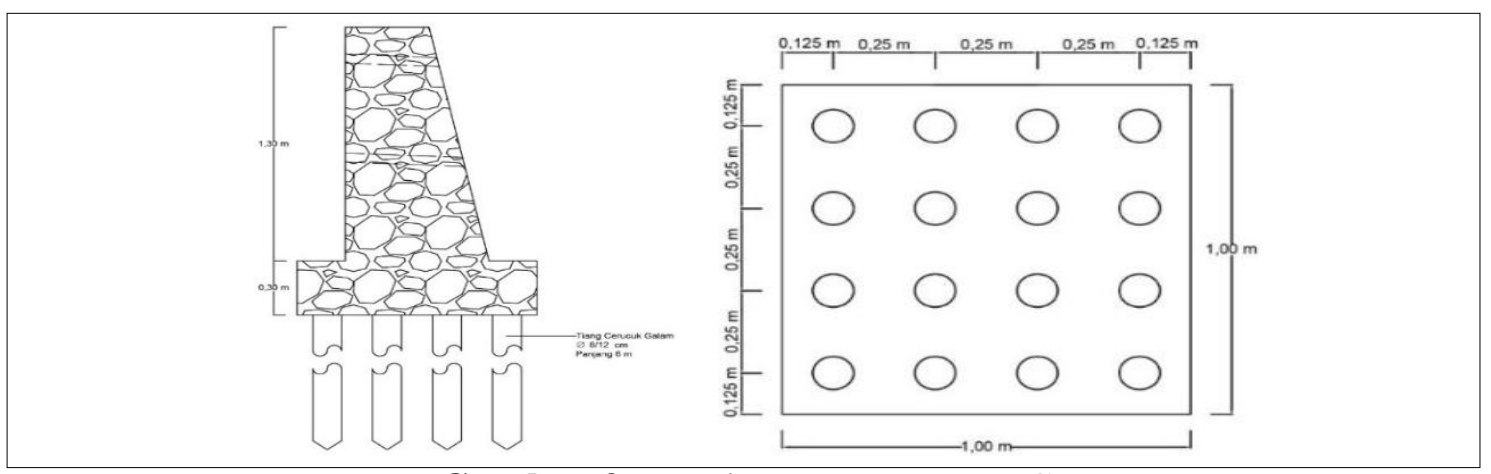

Gambar 3. Desain Pasangan Batu C

(Sumber: Hasil Analisis, 2020)

\section{PENUTUP}

\section{Kesimpulan}

Berdasarkan hasil perhitungan desain pasangan batu dan desain fondasi tiang cerucuk galam, dapat disimpulkan sebagai berikut :

1. Terdapat tiga tipe desain pasangan batu untuk dinding penahan tanah pada bahu jalan.

a. Pasangan Batu A dengan dimensi berupa tinggi dinding sebesar 1,40 m, lebar atas sebesar 0,35 m, lebar bawah sebesar 1,00 m, lebar kaki dan tumit sebesar 0,20 m, serta tebal kaki dan tumit sebesar 0,30 m. Adapun hasil dari tiga kontrol stabilitas, yaitu stabilitas terhadap penggseran diperoleh nilai sebesar $F_{g s}=13,98$, stabilitas 
terhadap penggulingan nilainya sebesar $F_{g l}=6,75$, dan stabilitas terhadap keruntuhan daya dukung tanah sebesar $F=5,12$.

b. Pasangan Batu B dengan dimensi berupa tinggi dinding sebesar $1,50 \mathrm{~m}$, lebar atas sebesar 0,35 m, lebar bawah sebesar 1,00 m, lebar kaki dan tumit sebesar 0,20 m, serta tebal kaki dan tumit sebesar $0,30 \mathrm{~m}$. Adapun hasil dari tiga kontrol stabilitas, yaitu stabilitas terhadap penggseran diperoleh nilai sebesar $F_{g s}=8,17$, stabilitas terhadap penggulingan nilainya sebesar $F_{g l}=5,85$, dan stabilitas terhadap keruntuhan daya dukung tanah sebesar $F=4,50$.

c. Pasangan Batu $\mathrm{C}$ dengan dimensi berupa tinggi dinding sebesar 1,60 m, lebar atas sebesar 0,35 m, lebar bawah sebesar 1,00 m, lebar kaki dan tumit sebesar 0,20 m, serta tebal kaki dan tumit sebesar $0,30 \mathrm{~m}$. Adapun hasil dari tiga kontrol stabilitas, yaitu stabilitas terhadap penggseran diperoleh nilai sebesar $F_{g s}=5,69$, stabilitas terhadap penggulingan nilainya sebesar $F_{g l}=5,13$, dan stabilitas terhadap keruntuhan daya dukung tanah sebesar $F=3,97$.

2. Desain fondasi tiang cerucuk galam sebagai tambahan perkuatan daya dukung tanah terhadap beban konstruksi pasangan batu sebanyak enam belas tiang galam dengan diameter tiang galam sebesar 8/12 cm, jarak antar tiang cerucuk galam sebesar $0,25 \mathrm{~m}$ dan kedalaman tiang galam sebesar $6,00 \mathrm{~m}$. Adapun kontrol terhadap perkuatan daya dukung tanah untuk ketiga tipe pasangan batu diperoleh nilai sebesar $Q_{T}=34,32 \mathrm{kN}$, dimana nilai tersebut melebihi total berat dari masing-masing tipe pasangan batu.

a. Pasangan Batu A dengan 34,32 $\geq 23,02$.

b. Pasangan Batu B dengan 34,32 $\geq 24,39$.

c. Pasangan Batu $\mathrm{C}$ dengan $34,32 \geq 25,75$.

\section{Saran}

Dari hasil perhitungan desain pasangan batu dan desain fondasi tiang cerucuk galam, maka dapat disarankan sebagai berikut :

1. Untuk merencanakan dinding penahan tanah harus mengetahui kondisi lapangan agar dapat mempermudah menentukan jenis dan dimensi yang tepat.

2. Penulis tidak dapat melakukan pengujian sampel tanah dari lokasi penelitian di laboratorium dikarenakan adanya pandemi covid-19, maka data yang digunakan berupa data studi literatur baik dari jurnal maupun laporan penelitian yang memiliki lokasi terdekat dengan lokasi penelitian. Sehingga diharapkan untuk penelitian selanjutnya dapat melakukan pengujian sampel tanah langsung dari lokasi penelitian di laboratorium untuk mendapatkan nilai yang lebih akurat.

3. Penelitian selanjutnya dapat menggunakan bantuan dari program Plaxis untuk menganalisis deformasi, tegangan-tegangan, daya dukung tanah, stabilitas dan lainlain dalam bidang geoteknik.

\section{DAFTAR PUSTAKA}

1. Ahmad Marzuki, Muhammad Firdaus, Ilhami dan Sidik Sutiasno. 2012. Evaluasi Perkiraan Daya Dukung Teoritis Tiang Berdasarkan Data Sondir (CPT) Dan Dial Pressure Load (Studi : Proyek Pembangunan Rumah Sakit Gigi Dan Mulut Banjarmasin). Jurnal Poros Teknik, Vol. 4, No. 2 (41 - 50).

2. Dedek Solehuddin, Efan Tifani, Zulkarnaen. 2018. Perencanaan Dinding Penahan Tanah (Studi Kasus : Jalan Lingkar Barat Duri). Jurnal Seminar Nasional Industri dan Teknologi (SNIT), Politeknik Negeri Bangkalis. 46 : 397 - 406. 
3. Departemen Pekerjaan Umum. 1987. Petunjuk Perencanaan Tebal Perkerasan Lentur Jalan Raya Dengan Metode Analisa Komponen. Jakarta : Yayasan Badan Penerbit PU.

4. Deyva Anggita Marpaung, dan Roesyanto. 2012. Analisis Daya Dukung Sistem Pondasi Kelompok Tiang Tekan Hidrolis (Studi Kasus Pada Proyek Pembangunan ITC Polonia Medan). Jurnal Teknik Sipil USU Vol. 1, No 2.

5. Direktorat Penyelidikan Masalah Bangunan. 1981. Peraturan Pembebanan Indonesia Untuk Gedung 1983. Bandung : Yayasan Lembaga Penyelidikan Masalah Bangunan.

6. Dona Dwi Saputro dan Haryo Koco Buwono. 2013. Studi Pengaruh Jarak Tiang Pancang Pada Kelompok Tiang Terhadap Perubahan Dimensi Pile Cap. Jurnal Konstruksia, Vol. 5, No. 1 (85-93).

7. Hardiyatmo, Hary Christady. 2002. Mekanika Tanah I (Edisi Ketiga). Yogyakarta : Gadjah Mada University Press.

8. Hardiyatmo, Hary Christady. 2003. Mekanika Tanah II (Edisi Ketiga). Yogyakarta : Gadjah Mada University Press.

9. Hardiyatmo, Hary Christady. 1996. Teknik Fondasi 1. Jakarta : PT Gramedia Pustaka Utama.

10. Hardiyatmo, Hary Christady. 2003. Teknik Fondasi 2 (Edisi keempat). Jakarta : PT Gramedia Pustaka Utama.

11. Hendra Setiawan. 2011. Perbandingan Penggunaan Dinding Penahan Tanah Tipe Kantilever dan Gravitasi Dengan Variasi Ketinggian Lereng. Jurnal Infrastruktur Vol. 1, No. 2, (88-95).

12. Herwin, Eka Priadi, dan Aprianto. 2017. Kajian Efisiensi Pada Kelompok Tiang Dengan konfigurasi $2 \times 2$. Jurnal Mahasiswa Teknik Sipil Universitas Tanjungpura Vol. 4, No. $4(1-11)$.

13. Irvan Nurrohman, Niken Silmi Surjandari, dan Noegroho Djarwanti. 2017. Analisis Dinding Penahan Tanah Tipe Gravitasi Pada Lereng Di Desa Sumbersari, Tirtomoyo, Wonogiri. Jurnal Matriks Teknik Sipil Vol. 5, No. 3 (1139-1146).

14. Kementerian Pekerjaan Umum dan Perumahan Rakyat Direktorat Jenderal Bina Marga. 2018. Spesifikasi Umum 2018 untuk Pekerjaan Jalan dan Jembatan. Jakarta : Direktorat Jenderal Bina Marga.

15. Melania Kalalo, Jack H. Ticoh, Agnes T. Mandagi. 2017. Analisis Stabilitas Dinding Penahan Tanah (Studi Kasus : Sekitar Areal PT. Trakindo, Desa Maumbi, Kabupaten Mihasa Utara). Jurnal Sipil Statik. Vol. 5 (285 - 294) ISSN : 2337 6732.

16. Muhammad Nasrudin, Siswoyo. 2019. Perencanaan Ulang Dinding Penahan Tanah Underpass Mayjend Sungkono Surabaya. Jurnal Axial Rekayasa dan Manajemen Konstruksi Vol. 7, No. 3 (227 - 240) ISSN 2615-0824.

17. Sriyati Ramadhani. 2010. Perencanaan Dinding Penahan Tipe Gravitasi Pada Lokasi Bukit BTN Teluk Palu Permai. Jurnal SMARTek. Vol. 8, No. 1 (34 - 39).

18. Suhudi, Andreas, Kiki Frida Sulistiani. 2017. Perencanaan Dinding Penahan Pasangan Batu Kali Pada Sungai Celaket Desa Gading Kulon Kecamatan Dau Kabupaten Malang. Jurnal Reka Buana. Vol. 2, No. 2 (106 - 113).

19. Sukirman, Silvia. 2010. Perencanaan Tebal Struktur Perkerasan Lentur. Bandung : Penerbit Nova.

20. Sunggono Kh. 1984. Buku Teknik Sipil. Bandung : Penerbit Nova.

21. Surendro, Bambang. 2015. Mekanika Tanah - Teori, Soal, dan Penyelesaian. Yogyakarta : CV. Andi Offset. 
22. Syafruddin. 2004. Desain Dinding Penahan Tanah (Retaining Walls) di Tanah Rawa Pada Proyek Jalan. Jurnal Info - Teknik Vol. 5, No. 2 (103 - 109).

23. Pemerintah Indonesia. 2004. Undang-Undang Republik Indonesia Nomor 38 Tahun 2004 tentang Jalan. Lembaran RI Tahun 2004 No. 38. Jakarta : Sekretariat Negara.

24. Pemerintah Indonesia. 2009. Undang-Undang Republik Indonesia Nomor 22 Tahun 2009 tentang Lalu Lintas dan Angkutan Jalan. Lembaran RI Tahun 2009 No. 22. Jakarta : Sekretariat Negara.

25. Riska Rahmawati Djunaedi. 2020. Perencanaan Dinding Penahan Tanah Tipe Gravitasi (Studi Kasus : SDN Lio, Kecamatan Cireunghas)). Jurnal Student Teknik Sipil Vol. 1, No. 2 (55 - 64) ISSN : 2686-5033.

26. Tjokorda Gde Suwarsa Putra, Made Dodiek Wirya Ardana, dan Made Aryati. 2010. Analisis Stabilitas Lereng Pada Badan Jalan dan Perencanaan Perkuatan Dinding Penahan Tanah (Studi Kasus : Jalan Raya Selemadeg, Desa Bantas, Kecamatan Selemadeg Timur). Jurnal Ilmiah Teknik Sipil Vol 4, No. 1 (36-42). 